\title{
Develop a Scenario for Da Nang as a Low Carbon City
}

\author{
Hoa Thai Nguyen
}

\begin{abstract}
The Vietnam Intended Nationally Determined Contributions (INDC) sets the target to reduce 8-25\% of total emissions in 2030 compared to Business as Usual (2030BaU). Therefore, the study of developing a Low Carbon City (LCC) for Da Nang aims to respond the national target. Two scenarios are developed for the socio-economic vision of Da Nang by 2030, with the projection of energy consumption and carbon dioxide $\left(\mathrm{CO}_{2}\right)$ emission in energy-related categories such as Residential, Commercial, Transportation, and Industry. The study shows that with proposal of five actions including 32 projects, Da Nang can reduce $19 \%$ total $\mathrm{CO}_{2}$ emission in countermeasure scenario $(2030 \mathrm{CM})$. This result is expected to be useful for researchers and policy-makers who are interested in developing the Climate Change Action Plan (CCAP) and to support the vision of building green growth for Da Nang city.
\end{abstract}

Index Terms—Low carbon city, INDC, Da Nang, Viet Nam

\section{INTRODUCTION}

Recently, major cities in Vietnam are required to localize the initiatives of the Intended Nationally Determined Contributions (INDC) to the United Nations Framework Convention on Climate Change (UNFCCC). The aim of INDC is to reduce $8-25 \%$ of total emissions in 2030 compared to Business as Usual (BaU). In line with the target, the Vietnam Green Growth Strategy (Decision 1393/QD-TTG approved by the Vietnamese Prime Minister in September 2012) aims to ensure efficient and sustainable economic growth in Vietnam while making significant contributions towards implementing the national climate change strategy. Moreover, the National Target Program for Climate Change Response (Decision 158/QD-TTG approved by the Vietnamese Prime Minister in December 2008) requires local governments to develop Climate Change Action Plans (CCAP). The CCAP is necessary and should be integrated with the middle- and long-term master plan of socio-economic development, specific sectoral development plans (such as transportation, industry, power, agriculture, etc.) as well as water and waste management.

Two scenarios are developed for the socio-economic vision of Da Nang by 2030, with the projection of energy consumption and $\mathrm{CO}_{2}$ emission in energy-related categories such as Residential, Commercial, Transportation, and Industry. They are 2030BaU (Business as Usual) and 2030CM (Countermeasures). The 2030BaU scenario, where countermeasures for greenhouse gas (GHG) emissions reduction are not introduced, reflects the situation in which both, the levels of commitments to climate-friendly-energy

Manuscript received September 8, 2016; revised October 20, 2016. This work was supported by JSPS Grant Number 15K06277.

Hoa Thai Nguyen is with Ritsumeikan University, 525-8577 Shiga, Japan (e-mail: nthaihoa@fc.ritsumei.ac.jp). production and technological breakthroughs are relatively low. Specially, countermeasures are assumed the same level as in 2013. On the other hand, the 2030CM scenario, which additional low carbon countermeasures are introduced in order to assess the reduction effects of GHG emissions. The socioeconomic assumptions about population, industrial structure, and economic growth are common to both scenarios. Information from many domestic sources is used to calibrate the parameters for base year 2013. In target year 2030, Extended Snapshot Tool (ExSS) is applied for the projection of future energy consumption and $\mathrm{CO}_{2}$ emission in energy-related categories.

\section{Methodology}

In order to identify the necessary actions, an "integrated modeling" based on "back-casting" approach is used. The back-casting approach sets a vision of the future society as a goal, and then seeks a pathway towards achieving that goal. We used ExSS (Extended Snapshot tool) for socio-economic indicators, energy related sectors. Information collection is the first step in the modeling work.

Socio-economic information as well as environmental information for the base year (2013) was collected and analyzed in order to estimate current carbon emissions. Besides this, feasible low carbon measures for Da Nang low carbon in the year 2030 were also collected.

For the future projection, information is based on planned developments, as the model estimates socio-economic activity levels including population, number of households, land area, transport demand and other variables. Based on the collected information, GHG emissions are calculated with or without countermeasures.

ExSS is a simplified simulation model for low carbon study and projects socio-economic activity, energy demand and supply, GHG emissions and emission reduction by measures. While each part of the tool is relatively simple, it can describe whole picture of future society as a LCC in a quantitative and consistent manner with a greater flexibility than many other models. It also can consider most of the low carbon measures existing and expected in near future. In this simulation model, population is decided by demand from outside of the region, labor participation ratio, demographic composition and relationship of commuting with outside of the region. To determine output of industries, input-output approach is applied. Passenger transport demand is estimated from the population and freight transport demand whereby it is a function of output by manufacturing industries. Floor area of commerce is determined from output of tertiary industries. Other than driving force, activity level of each sector, energy demand by fuels determined with three parameters. One is energy service demand per driving force, energy efficiency 
and fuel share. Diffusion of counter measures changes the value of these parameters, and so GHG emissions.

\section{RESULTS}

\section{A. Demography}

Following the goal is to develop Da Nang into a major city for the economy and to make Da Nang the socio-economic center of central Vietnam. The estimation of social and economic growth is based on the Study on Integrated Development Strategy for Da Nang City and Its Neighboring Area in the Socialist Republic of Vietnam (DaCRISS) [1]. With assumption of population growth rate of 3\%, Da Nang's population is projected to be more than 1.64 million people, which about 1.66 times increase on the base year's population 2013 [2]. Household size in 2030 is assumed by 3 persons/household (smaller than the calculated value for 2013, which is 3.4), the total number of households increases 1.9 times, reaching about 548 thousand households in 2030.

\section{B. Economy}

Da Nang has recorded remarkable changes in economic development. The economic structure of Da Nang city continues to shift towards the industries and services. According to the development targets in Da Nang's development master plan, it is estimated that the gross domestic product (GDP) in 2030 will increase 4.91 times compared to 2013. In 2013, the commercial sector dominates the GDP share with $64.4 \%$, followed by industrial sector with $34.5 \%$. In 2030, due to the increase of growth rate in commercial compared to agricultural sectors, the share of commercial in total GDP increase to $65.2 \%$, while the share of industry decreases to $33.9 \%$, with a small share of less than $1 \%$ of total GDP is from agriculture. This economic structure follows the current trend and future vision of Vietnam towards the tertiary industrial economy. The GDP per capita of Da Nang in 2013 is around 52 mil. Dongs, and increases 2.97 times by 2030. The GDP per capita in 2030 reaches 154 mil. Dongs due to the rapid GDP growth (9.7\% per annual). In 2030, export and import in Da Nang expected to increase 4.83 and 4.75 times compared to those in 2013, respectively. Final consumption increases 4.83 times, in which main consumption is from households for industrial commodities and services while the government consumption is mainly for science, technology, and other services.

\section{Transport Demand}

The transport demand in 2030 increases dramatically from 8,642 to 12,426 million person per kilometer (mil.per.km) of passenger transport and 2,563 to 18,637 million ton per kilometer (mil.ton.km) of freight transport compared to 2013 due to the increasing population and industrial activities.

In passenger transport, there is a rapid increase of demand on car to 3.61 times, even motorbike still dominates. The share of public transport by trip increases from $0.6 \%$ in 2013 to $10.0 \%$ in $2030 \mathrm{BaU}$ and reaches $24.5 \%$ in $2030 \mathrm{CM}$ due to the contribution of public bus system.

Freight transport relies predominantly on roads and followed by waterway [3]. We assumed that the share of waterway by trip will increase in freight transport modes in 2030 , in which road is still dominates and contributes to $80 \%$, followed by waterway with $20 \%$ contribution.

\section{Final Energy Consumptions}

Energy balance table in 2013 and 2030 for Da Nang was estimated based on information in the DaClimb report [4], Energy Balances of non-OECD 2014 FIG [5] and Nguyen [6].

The annual total final energy consumption of residential, commercial, industrial and transport sectors is expected to increase from 702 kilo tonnes oil equivalent (ktoe) in 2013 to 2,527 ktoe in 2030BaU scenario and 2,010 ktoe in 2030CM scenario.

The share of energy consumption by residential sector is projected to be reduced substantially from $11 \%$ in 2005 to $4.6 \%$ in $2030 \mathrm{BaU}$ and $2030 \mathrm{CM}$ scenarios, as a result of a reduction of the traditional biomass fuels for cooking. In transport sector, energy consumptions are accounting for $50.1 \%$ and $47.6 \%$ in $2030 \mathrm{BaU}$ and $2030 \mathrm{CM}$ scenarios, respectively.

The finding shows that the energy shares of industrial and commercial sectors are expected to increase in future, while the share of residential and transport sectors decrease. This is because of continued trends of industrialization and increasing travel demand per person.

The energy intensity by GDP reduces from 13.6 toe/bil. Dongs in 2013 to 10.6 toe/bil. Dongs in 2030BaU and 8.5 toe/bil. Dongs in 2030CM due to the lower increasing rate of energy consumption compared to the rapid growth of GDP. This reduction follows the target to reduce $1 \%$ to $1.5 \%$ per year as mentioned in Decision 1393/QD-TTg for "National Green Growth Strategy".

In $2030 \mathrm{BaU}$, the total energy consumption is 1.73 times higher than 2013, increasing from 6,972 ktoe to 12,056 ktoe. In which, industry is still the main energy consumer with $59.4 \%$ (1.83 times increase), followed by transport sector with $20.4 \%$. Commercial sector has the highest speed of energy consumption with 2.18 times increase and its share is $10.1 \%$.

In term of energy consumption mix, there is a switch from coal and oil consumption to natural gas and electricity. However, coal and gas are still main energy sources with the share of coal and oil consumption from $68.2 \%$ in 2013 to $67.0 \%$ in $2020 \mathrm{BaU}$, especially for industrial activities. A small share of total final energy consumption is from biomass for some purposes in residential and commercial sectors.

\section{E. GHG Emissions in Da Nang City}

Emission factors in this study were referred to 2006 IPCC Guidelines for National Greenhouse Gas Inventories [7].

In the year 2013, estimated GHG emission is about 2.7 $\mathrm{MtCO}_{2}$ eq. In 2030BaU, total GHG emission increased up to 10.7 $\mathrm{MtCO}_{2}$ eq, about fourfold increase from 2013. In which, the major contributors to GHG emission include industrial sector (46.2\% of total GHG emissions in 2030BaU scenario), followed by transport, commercial and residential sectors which account for $37.1 \%, 9.3 \%$ and $7.5 \%$ of total $\mathrm{GHG}$ emissions in the $2030 \mathrm{BaU}$ scenario, respectively.

In $2030 \mathrm{CM}$, emissions estimated reduced by $19 \%$ from the $2030 \mathrm{BaU}$ emissions. In which, highest reduction is attributes 
to transport sector (46\%), followed by industry (38\%), commercial (8\%) and residential (8\%).

TABLE I: Climate Change ACtions $\left(\mathrm{KTCO}_{2}\right)$ FOR DA NANG CiTY

\begin{tabular}{|c|c|c|c|c|}
\hline Action & & Project & Sector & $\begin{array}{l}\text { Emission reduction } \\
\quad\left(\mathrm{ktCO}_{2} \mathrm{eq}\right)\end{array}$ \\
\hline \multirow[t]{3}{*}{1 Smart Industry } & $1-01$ & ESCO (Energy Saving Company) project for industries & Industry & 192.4 \\
\hline & $1-03$ & Regional energy supply system & Industry & 108.3 \\
\hline & $1-04$ & Improvement of kiln and furnace technology & Industry & 272.0 \\
\hline \multirow[t]{7}{*}{2 Smart Building } & $2-01$ & Installation of insulated glasses to commercial buildings & Commercial & 6.4 \\
\hline & $2-02$ & Installation of insulated glasses to households & Residential & 5.1 \\
\hline & $2-03$ & Introduction of incentive to low energy buildings & Commercial & 2.0 \\
\hline & $2-04$ & Introduction of insulating material to houses & Residential & 32.3 \\
\hline & $2-05$ & Energy efficiency technology applied to buildings & Commercial & 5.5 \\
\hline & $2-07$ & Introduction of solar water heater to households & Residential & 23.5 \\
\hline & & ( & & 96.2 \\
\hline \multirow[t]{8}{*}{3 Energy Efficiency } & $3-01$ & ESCO (Energy Saving Company) project for commercial buildings & Commercial & 27.8 \\
\hline & $3-02$ & High efficiency lighting in public lighting & Commercial & 4.2 \\
\hline & $3-03$ & High efficiency lighting in commercial buildings & Commercial & 49.8 \\
\hline & $3-04$ & High efficiency lighting in households & Residential & 32.8 \\
\hline & $3-05$ & $\begin{array}{l}\text { High efficiency air conditioners (such as air conditioners with inverter controllers) } \\
\text { in commercial buildings }\end{array}$ & Commercial & 31.2 \\
\hline & $3-06$ & $\begin{array}{l}\text { High efficiency air conditioners (such as air conditioners with inverter controllers) } \\
\text { in commercial households }\end{array}$ & Residential & 23.8 \\
\hline & $3-07$ & Promotion of energy-efficient appliances & Residential & 63.8 \\
\hline & & Total & & 233.4 \\
\hline \multirow{10}{*}{4 Smart Transport } & $4-02$ & Wide-range traffic control & Transport & 3.9 \\
\hline & $4-03$ & Expansion of frequencies and routes of bus transportation & Transport & 5.3 \\
\hline & $4-04$ & Development of Bus Rapid Transit (BRT) & Transport & 2.7 \\
\hline & $4-05$ & Shift to CNG bus & Transport & 6.1 \\
\hline & $4-06$ & Introduction of electric motorbikes & Transport & 32.0 \\
\hline & $4-07$ & Promotion of energy-efficient vehicles (cars for passenger) & Transport & 52.4 \\
\hline & $4-08$ & Promotion of energy-efficient vehicles (motorbikes) & Transport & 73.3 \\
\hline & $4-09$ & Promotion of energy-efficient vehicles (trucks) & Transport & 348.4 \\
\hline & $4-10$ & Development of water freight transport system & Transport & 398.8 \\
\hline & & Total & & 951.5 \\
\hline \multirow[t]{5}{*}{5 Green Energy } & $5-01$ & Introduction of photovoltaic power generation to commercial buildings & Commercial & 4.7 \\
\hline & $5-02$ & Introduction of photovoltaic power generation to households & Residential & 4.7 \\
\hline & $5-03$ & Introduction of small-scale hydropower generation (at water distribution stations) & Commercial & 1.6 \\
\hline & $5-04$ & Introduction of wind power generation & Commercial & 9.8 \\
\hline & & Total & & 20.8 \\
\hline Total & & & & $2,078.9$ \\
\hline
\end{tabular}

In 2013, per capita GHG emissions in Da Nang was 2.7 $\mathrm{tCO}_{2} \mathrm{eq}$, though, in $\mathrm{BaU}$ scenarios, it is projected to increase up to $6.5 \mathrm{tCO}_{2}$ eq. In $2030 \mathrm{CM}$ scenario it can be reduced to 5.2 $\mathrm{tCO}_{2}$ eq.

In 2013, estimated GHG emission intensity is 51.6 $\mathrm{tCO}_{2}$ eq/bil.dongs. In 2030BaU, emission intensity decreased to $42.2 \mathrm{tCO}_{2} \mathrm{eq} / \mathrm{bil}$.dongs mainly because of greater share of tertiary industry in GDP. In 2030CM scenario, which introduces implementation of the projects and actions, emission intensity is estimated to $34 \mathrm{tCO}_{2} \mathrm{eq} / \mathrm{bil}$.dongs.

\section{F. GHG Emission Reduction by Actions}

GHG emission reduction in Da Nang city by Actions is shown in Table I. Detail of each Action is described below:

Action 1. Smart Industry. Low carbon projects regarding promotion of energy efficient equipment and fuel shift in the industry sector is included in Action 1. Total reduction of GHG emissions by this action is $777 \mathrm{ktCO}_{2}$ eq. Improvement of kiln and furnace technology such as waste heat recovery is one of the main project in Action 1. This project contributes to 
reduce $272 \mathrm{ktCO}_{2} \mathrm{eq}$.

Action 2. Smart Building. This action covers low carbon projects related with diffusion of low-energy houses and buildings. This action can reduce $92 \mathrm{ktCO}_{2} \mathrm{eq}$. Energy demand in houses and buildings through projects such as diffusion of energy management system and installation of insulated glasses. Introduction of insulating material to houses is a project that reduce the largest GHG emission in this action. Introduction of solar water heater to houses and buildings is also main projects in this action to reduce fuel demand. $\mathrm{CO} 2$ emission from houses is reduced by 23 $\mathrm{ktCO}_{2}$ eq through $20 \%$ diffusion of solar water heater.

Action 3. Energy Efficiency. Projects about promoting energy efficient device and appliance like lighting and air conditioners for houses and buildings are covered in Action 3. Total reduction of GHG emission by this action is 233 $\mathrm{ktCO}_{2}$ eq. For instance, replacement of conventional lighting by high efficient one such as LED lighting in houses and buildings contributes to reduce $87 \mathrm{ktCO}_{2} \mathrm{eq}$.

Action 4. Smart Transport. It is estimated that projects in Action 4 can reduce $952 \mathrm{ktCO}_{2} \mathrm{eq}$ in total, which is the largest reduction among all actions. This action covers variety of projects regarding both passenger and freight transportation. Not only improvement of fuel efficiency of vehicles but also promotion of modal shift to public transportation and deployment of CNG bus are listed. Projects for freight transport such as promotion of energy-efficient trucks have large potential to reduce GHG emissions, because GHG emission from freight transport sector is more than twice as high as that from passenger transport sector. Development of water freight transport system is aimed to shift freight transportation from truck to ship. Meanwhile, projects like introduction of electric motorbike and CNG bus contribute to reduce $\mathrm{GHG}$ emission from passenger transport.

Action 5. Green Energy. This action covers projects for increasing electric power generation by renewable energy including photovoltaic power, wind power and small-scale hydropower. Total reduction of GHG emission by Action 5 is $21 \mathrm{ktCO}_{2}$ eq. Photovoltaic power generation systems are assumed to install on rooftop of houses and buildings. Hydropower generation is introduced to public facilities such as water distribution station.

\section{CONCLUSIONS}

Several main output of the study can be drawn out as below:

In 2030BaU, Da Nang is expected under the rapid growth of driving forces such as population, transport demand, and industrial activities; the total GHG emissions increases 4.01 times, from 2,665 $\mathrm{ktCO}_{2}$ eq in 2013 to $10,687 \mathrm{ktCO}_{2}$ eq.

In 2030CM, the total GHG emissions reduction is $19 \%$, accounting for $2078 \mathrm{ktCO}_{2}$ eq. Da Nang can reduce such emissions reductions by implementing 35 projects grouped in five actions.

By implementing five climate change actions, namely; Smart Industry (4 projects), Smart Building (7 projects), Energy Efficiency (7 projects), Smart Transport (10 projects) and Green Energy (4 projects), Da Nang can reduce 19\% total GHG emissions in 2030CM (between the 10-20\% national reduction target as declared in the Green Growth strategy and within $8-25 \%$ mentioned in the Vietnam's INDC).

\section{ACKNOWLEDGMENT}

I would like thank our colleagues Prof. Matsuoka from Kyoto University, Dr. Fujino from Institute for Global Environmental Strategies/ National Institute for Environmental Studies in Japan and Mr. Ochi from E-konzal for their providing insight and expertise that greatly assisted the research. I would also like to be immensely grateful to Prof. Amano, Prof. Shimada and Dr. Yoshikawa in Ritsumeikan University for their comments and supports to complete this research."

\section{REFERENCES}

[1] The Study on Integrated Development Strategy for Da Nang city and Its Neighboring Area in the Socialist Republic of Vietnam (DaCRISS), JICA and Da Nang People's Committee, 2010.

[2] Report of Projection of Population in Da Nang by 2030 (in Vietnamese), Da Nang Statistical Office, 2015.

[3] Da Nang City Statistical Yearbook 2013, Da Nang Statistical Office, 2014.

[4] Da Nang Climate Change Mitigation for Buildings (DaClimb), Da Nang Climate Change Coordination Office (CCCO), 2014.

[5] Energy Balances of non-OECD 2014, International Energy Agency (IEA), 2014

[6] T. Nguyen, "A low carbon society development towards 2030 in Vietnam,” Ph.D. dissertation, Dept. Environmental Eng., Kyoto Univ., Kyoto, Japan, 2012.

[7] 2006 IPCC Guidelines for National Greenhouse Gas Inventories, The United Nations Intergovernmental Panel on Climate Change, 2006.

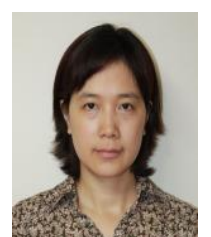

H. T. Nguyen was born in Vietnam in May 19, 1981. She obtained the bachelor's degree from National University of Civil Engineering, Hanoi, Vietnam in 2004; the master's degree from Institute of Asian Technology (AIT), Bangkok, Thailand in 2007 and the Ph.D.'s degree from Kyoto University, Kyoto, Japan in 2012. Her major is environmental engineering which including low carbon society, waste management, water and wastewater treatment and climate change studies.

Nguyen has worked for Thuy Loi University as a lecture in Hanoi, Vietnam from 2007 to 2009 . From 2012 to 2016 she has worked as a program-specific researcher in Kyoto University, Japan. From September 2016, she has started working as a senior researcher in BKC Research Organization of Social Sciences which is belong to Ritsumeikan University, Shiga, Japan. Several publications of author such as H.T. Nguyen and Y. Matsuoka, "The analysis of greenhouse gas emissions/reductions in waste sector in Vietnam," Mitigation and Adaptation Strategies Global Change. Springer, Article in press. DOI 10.1007/s11027-015-9679-3/2015; H.T. Nguyen, K. Gomi, Y. Matsuoka, "Low Carbon Energy Scenario Development in Vietnam," International Proceeding of Chemical, Biological, Environmental Engineering, pp.1-6, vol. 61, Singapore: IACSIT Press, 2014; H.T. Nguyen, T. Hasegawa and Y. Matsuoka, "Climate change mitigation strategies in agriculture, forestry and other land use sectors in Vietnam," Mitigation and Adaptation Strategies Global Change. Springer, vol. 19(1), pp 15-32, 2012. Currently, Nguyen researches on Low Carbon City development for Asian countries.

Dr. Nguyen has been a senior member of Asian-Pacific Chemical, Biological and Environmental Engineering Society since 2014. She received the outstanding student paper awarded by the Scientific Committee of 17th Annual International Sustainable Development Research Conference, the Earth Institute, Columbia University, New York, USA in May 2011. 